\title{
A single Epley manoeuvre can improve self-perceptions of disability (quality of life) in patients with cp-BPPV: A randomised controlled trial in primary care.
}

Ricard Carrillo Muñoz

Institut Catala De La Salut

Jose Luis Ballve Moreno ( $\sim$ ballvejl@gmail.com )

Institut Catala De La Salut https://orcid.org/0000-0002-4911-4477

Ivan Villar Balboa

Institut Catala De La Salut

Yolanda Rando Matos

Institut Catala De La Salut

Oriol Cunillera Puertolas

Institut Catala De La Salut

Estrella Rodero Perez

Institut Catala De La Salut

Xavier Monteverde Curto

Institut Catala De La Salut

Carles Rubio Ripollès

Institut Catala De La Salut

Noemi Moreno Farres

Institut Catala De La Salut

Olga Lucia Arias Agudelo

Institut Catala De La Salut

Jesus Almeda Ortega

Institut Catala De La Salut

Research article

Keywords: Benign paroxysmal positional vertigo, primary health care, Epley maneuver, health-related quality of life, randomised controlled trial

Posted Date: October 30th, 2020

DOI: https://doi.org/10.21203/rs.3.rs-36678/v2

License: () (1) This work is licensed under a Creative Commons Attribution 4.0 International License. Read Full License 


\section{Abstract}

Background: Posterior canal benign paroxysmal positional vertigo (pc-BPPV) causes physical, functional, and emotional impairment. The treatment of choice is the Epley manoeuvre (EM). The purpose of the study was to compare the impact of the EM and a sham manoeuvre in primary care on self-perceived disability.

Method: Randomised, double-blind, sham-controlled clinical trial conducted in primary care with a follow-up of 1 year. Patients aged $\geq 18$ years old diagnosed with pc-BPPV according to the Dix-Hallpike test (DHT) were randomised to an intervention (EM) group or a control (sham manoeuvre) group. The main study covariables were age, sex, history of depression and anxiety, presence of nystagmus in the DHT, patient-perceived disability assessed with the Dizziness Handicap Inventory-screening version (DHI-S). Data were analyzed using bivariate and multivariate mixed Tobit analyses.

Results: Overall, 134 patients were studied: 66 in the intervention group and 68 in the control group. Median age was 52 years (interquartile range [IQR], 38.25-68.00 years) and $76.12 \%$ of the patients were women. The DHT triggered nystagmus in $40.30 \%$ of patients. The median total DHI-S score for the overall sample at baseline was 16 (IQR, 8.00-22.00); 16 [IQR, 10.5-24.0] vs 10 [6.0-14.0] for women vs men $(P<0.001)$ and 16 [IQR, 10.0-24.0] vs 12 [IQR, 8.0-18.0] for patients without nystagmus vs those with nystagmus $(P=0.033)$. Patients treated with the EM experienced a mean reduction of 2.03 points in DHI-S score over the follow-up period compared with patients in the sham group.

Conclusion: Pc-BPPV affects the quality of life of primary care patients. A single EM can improve selfperceptions of disability by around 2 points on the DHI-S scale,

Trial registration : ClinicalTrials.gov Identifier: NCT01969513. Retrospectively registered. First Posted: October 25, 2013. https://clinicaltrials.gov/ct2/show/NCT01969513

\section{Background}

Benign paroxysmal positional vertigo (BPPV), the most frequent cause of vertigo, has an annual incidence ranging from 10.7 to 140 cases per 100000 inhabitants [1] and a lifetime prevalence of 2.4\% [2]. According to one systematic review, between $4.3 \%$ and $39.5 \%$ of patients seen in primary care for dizziness had BPPV [3]. Posterior canal BPPV (pc-BPPV) is the most common variant and accounts for $60 \%$ to $90 \%$ of all cases [4].

Pc-BBPV can be diagnosed with relative ease in primary care, as a targeted history, a basic physical examination, and performance of the Dix-Hallpike test (DHT) are sufficient to establish a diagnosis [5]. The DHT is considered to be positive when it causes both vertigo and nystagmus. This form of BPPV is known as objective BPPV (OBPPV). According to some authors, however, the DHT may also be considered positive if the patient experiences symptoms without nystagmus [6]. This form of BPPV is known as subjective BPPV (S-BPPV) and it accounts for around $11.5 \%$ to $48 \%$ of all cases [7].

Many patients with BPPV experience impaired physical and functional performance and the condition can also have an effect on family and social life [8] [9]. Vertigo increases the risk of falls [10], particularly among elderly patients [11], and also causes psychological symptoms that can lead patients to avoid certain everyday situations [12]. 
Perceived disability among patients with BPPV is usually assessed using standardised questionnaires, the most common being the Dizziness Handicap Inventory (DHI) [13], for which several abbreviated versions have been created. One recent study comparing the original 25-item DHI with shorter versions reported that the Dizziness Handicap Inventory - Screening version (DHI-S) was the best option as it shows strong correlation with the original DHI ( $r=0.86)$ and has acceptable internal consistency (test-retest $r=0.95)$ [14]. The DHI-S was designed by Jacobson et al. [15] and consists of 10 questions with the same "yes, "sometimes" and "no" answer options as the original questionnaire. It is a self-administered questionnaire that can be completed in 4 to 5 minutes, making it suitable for use in centres that have to deal with large numbers of patients such as primary care practices. It has been validated for use in Spain [16].

The treatment of choice for BPPV is the Epley manoeuvre (EM), whose effectiveness has been demonstrated in numerous studies and systematic reviews [1][17][18][19]. The EM is a canalith repositioning manoeuvre that has been associated with improved self-perceptions of disability among patients with BPPV [16][20]. It has also proven effective in elderly patients [21] and in the long term, even after a single treatment [22].

Although performance of the EM is feasible in primary care [23], most of the studies that have evaluated its impact on perceived disability among patients with pc-BPPV have been performed in specialised clinics. Studies thus are needed to evaluate its impact in patients diagnosed and treated in primary care [1], and it was a secondary outcome of interest from our original clinical trial protocol [24].

Carrillo-Muñoz et al. analyzed quality of life perceived by primary care patients with pc-BBPV using baseline data from the original trial [9], while Ballvé et al measured the effectiveness of the Epley manoeuvre according to DixHallpike test results and perceived vertigo severity assessed on a Likert scale [25]. The current study, by contrast, analyzes the effectiveness of the Epley manoeuvre over a period of a year according to a psychometric scale of perceived disability. This complements clinical measurements by providing insights into patient perceptions of the different dimensions of pc-BPPV.

\section{Methods}

\section{Aim}

The aim of the study was to compare the effect of the EM and a sham manoeuvre on self-perceived disability assessed using the DHI-S at 1 week, 1 month, and 1 year in primary care patients with pc-BPPV.

\section{Trial design}

Randomised, double-blind, sham-controlled clinical trial with an allocation ratio of 1:1 conducted in two primary care practices.

\section{Changes to trial design}

Although vestibular migraine was not an exclusion criterion for the trial [24], emerging evidence on the high prevalence of this condition [26] and its overlapping symptoms with pc-BPPV suggested that patients with vestibular migraine might have been recruited for the trial. It was therefore decided to re-assess all patients after completion of the follow-up phase and to remove those who met the 2013 criteria for probable vestibular 
migraine [27]. Results following the original trial design, including patients with probable vestibular migraine, are presented as supplementary material

\section{Participants}

Patients were recruited between November 2012 and January 2015, and three follow-up visits, held a week, a month, and a year after the intervention, were performed by six general practitioners (GPs) blinded to treatment allocation working at two primary care practices, which employ 26 GPs and offer care for 38305 people in L’Hospitalet de Llobregat (Barcelona, Spain).

Eligible participants included all adults ( $\geq 18$ years) with symptoms of vertigo seen at the primary care practices, and patients clinically suspected to have pc-BPPV were systematically recruited by the GPs involved in the study. Patients who agreed to participate were referred for baseline evaluation by one of six GPs on the research team. Those who provided written informed consent and had a positive DHT, with or without nystagmus (O-BPPV or SBPPV, respectively), were included. Patients with purely vertical nystagmus, nystagmus lasting $>1$ minute, or vertical or alternating nystagmus were excluded and referred to an ear, nose, and throat (ENT) specialist. This was done because it was suspected that their nystagmus was caused by a condition other than pc-BPPV (possibly even central nystagmus). They would therefore have required further investigation (e.g., magnetic resonance imaging, computed tomography, referral to an ENT specialist) and this would have affected our results. The full list of exclusion criteria is available in the study protocol [24].

\section{Interventions and comparisons}

At the baseline visit, the patients underwent a full physical examination and a complete medical history, including review of electronic medical records.

Patients in the intervention group were treated with a single EM. They were prescribed betahistine $8 \mathrm{mg} / 8 \mathrm{~h}$ and instructed to use the medication as required (maximum 3 times a day) until their symptoms improved.

Patients in the control group were prescribed betahistine as the same dosage. Instead of the EM, however, they received a sham manoeuvre consisting of laying the patient with his/her head turned towards the affected side for 5 minutes [28].

The GPs who administered the EM took part in a 2-hour practical training session on diagnosing vertigo and applying the manoeuvre under the supervision of an ENT specialist to ensure consistent execution across patients. Two videos showing an investigator administering the DHT (https://www.youtube.com/watch? v=tJEFi5RFZEM) and the EM (https://www.youtube.com/watch?v=yAFx4-TFcGE) were also recorded.

\section{Variables}

Patient-perceived disability assessed using the total score on the DHI-S was used as the main outcome variable. The 10 items on the DHI-S are scored with 0 for "no", 2 for "sometimes", and 4 for "yes". The total possible score therefore ranges from 0 (no self-perceived disability) to 40 (worst possible self-perceived disability).

The independent variables were age, sex, DHT result (O-BPPV or S-BPPV), history of anxiety and/or depression (Yes/No) and treatment with benzodiazepines, antidepressants, and/or vertigo drugs (Yes/No) at the time of the 
baseline visit.

\section{Sample size}

The sample size was calculated for outcomes not analyzed in this study. Based on a sample size of 65 and 61 patients in the study arms at week 1 , the study had a power of $80 \%$ to detect a statistically significant difference (alpha $=0.05$ ) of 5.16 in DHI-S scores between groups (assuming a standard deviation of 10 [16] in a Wilcoxon test [power estimated by bootstrap]).

\section{Randomisation and allocation}

Patients were assigned to the intervention and control groups using a list of randomisation sequences prepared in advance by the study statistician. The randomisation sequences were generated in 'R: A language and environment for statistical computing', version 2.14.2 (R Foundation for Statistical Computing, Vienna, Austria). Two members of staff from the participating primary care practices not involved in the clinical trial were responsible for safeguarding the randomisation list. On completion of the baseline visit activities, the recruiting GPs contacted one of these members of staff to find out the randomisation number and arm to which the patient was to be assigned.

\section{Blinding}

The study was double blind. The GPs who performed the baseline visits did not participate in the follow-up visits, and vice-versa. GPs responsible for follow-up were therefore unaware of allocation. Randomisation data were not recorded in the data collection notebooks or database. Only the study statistician had access to this information.

\section{Statistics}

Continuous variables (e.g., DHI-S scores) were expressed as median and interquartile range (IQR), while categorical variables (e.g., anxiety) were expressed as absolute and relative frequencies. For the between-group comparisons at each time point, the distribution of DHI-S answers were compared using the Chi-square test, while DHI-S scores were compared using the Wilcoxon test. These bivariate analyses were performed for the overall samples and stratified by sex and presence or absence of nystagmus at baseline.

A longitudinal multivariate regression model was built using DHI-S scores. Given the considerable proportion of 0 scores, a full mixed-effects multivariate Tobit regression model was adjusted to explain DHI-S scores by intervention, baseline DHI-S score, sex, baseline diagnosis (O-BPPV vs S-BPPV), and three-way interactions between all these variables and the treatment group, with adjustment for correlated intraindividual observations. Stepwise backward variable selection using the Akaike information criterion (AIC) was applied to obtain the final model. This reduced Tobit model contained all relevant variables and interactions; results are presented as marginal effects (medians of individual effects [29] [30]) and statistical significance (p-value) of the associated coefficients.

\section{Results}


Of the 330 patients with suspected pc-BPPV analyzed, 134 (40.6\%) were included in the trial: 66 were randomised to the intervention group and 68 to the sham group. The reasons for exclusion are summarised in the study flowchart (Figure 1). The main reason for exclusion was a negative DHT at baseline $(n=123)$. Nineteen patients were removed retrospectively because they had criteria compatible with vestibular migraine. Their results, however, can be consulted in the supplementary material. The respective number of patients lost to follow-up at the three time points (week, month, and year) was 7, 17, and 21 . The baseline characteristics for the overall sample and the intervention and control groups are shown in Table 1. The median age was 52 years (IQR, 38.25-68.00, standard deviation, 16.98) and $76.12 \%$ of the patients were women. The DHT triggered nystagmus in $40.30 \%$ of patients (O-BPPV). The proportion of patients with anxiety and depression was $25.38 \%$ and $23.08 \%$, respectively. In total, $17.91 \%$ of patients were being treated with benzodiazepines, $20.15 \%$ with antidepressants, and $58.21 \%$ with vertigo drugs at the baseline visit. No significant differences were observed between the intervention and control group for any of the study variables. The median duration between symptom onset and visit (EM application) was 10.52 days [IQR= 5, 31]. The rate of subjects who referred having suffered at least a previous BPPV episode similar to the presenting one was $52.38 \%$.

Patient-perceived disability during the follow-up period (week, month, year) was not influenced by a history of anxiety or depression or treatment with anxiolytics. The final multivariate model (the model with the best performance according to the AIC) showed that variations in DHI-S scores were explained by treatment group, baseline DHI-S score, follow-up (time point), and interaction between DHI-S score and time. Baseline DHI-S score was positively associated with DHI-S score during follow-up, with an initial marginal effect of 0.37 at week 1 . The respective effects at 1 month and 1 year were 0.3 and 0.32 (significant decrease). According to the selection process, the interaction treatment $\times$ time did not provide the model with sufficient predictive accuracy for these coefficients to be retained. In the final model thus, the treatment effect did not vary significantly over time, showing a stable marginal effect of $-2.03(-4.59,-0.06)$ points (Table 3$)$. The expected DHI values estimated by the multivariate model in Table 3 are shown in Figure 2 according to the different exposure characteristics.

No statistically significant differences in DHI-S scores were observed between the intervention and control group at baseline or during follow-up according to sex or presence or absence of nystagmus at baseline (Tables $2 a, 2 b$, $2 \mathrm{c}$ and $2 \mathrm{~d})$.

\section{Discussion}

\section{Summary}

Patients' perceptions of pc-BPPV-associated disability assessed by the DHI-S improved after treatment with a single EM performed by GPs, with a significant difference in DHI-S scores of -2.03 points compared with the sham group over the follow-up period; no significant variations were observed during this period.

Although the difference of -2.03 points was significant, it may not have been clinically relevant, as the minimal detectable difference for the long version of the $\mathrm{DHI}$ is 17.68 points in the $0-100$ theoretical range [31]. Our results should, therefore, be interpreted with caution and it is important to consider the theoretical score ranges of the different versions of the DHI. We might also have observed greater differences if we had treated certain patients with more than one EM (the recommended number is up to four) [32]. 
The median age of the patients in our series is similar to that observed in other studies at specialised clinics [16] [31] and primary care practices [23].

Also supporting previous findings [2] [20] [33] [34], women outnumbered men in our study, which is consistent with the higher prevalence of pc-BPPV in women [35] [36][37][38]. No significant differences between men and women were found in terms of response to the EM during follow-up, even though baseline DHI-S scores were higher among women. Sex was not a significant factor in the multivariate model. Pereira et al [20] also reported similar responses to the EM in men and women.

The main strength of our study is that it was conducted under typical conditions encountered in primary care practices, which is where most patients with BPPV are seen.

The higher proportion of patients with S-BPPV detected in our series compared with earlier series [14] [40] indicates that we may have underestimated the prevalence of O-BPPV. Patients seen in primary care often have early-stage nystagmus, which is more difficult to diagnosis, particularly if special tools such as Frenzel goggles or videonystagmography are not used [41]. The gold standard diagnostic work-up for pc-BPPV does not include these tools [1], but they can increase the number of O-BPPV cases diagnosed. Testing primary care patients with S-BPPV in addition to those with O-BBPV (greater diagnostic sensitivity at the expense of specificity) in primary care may improve early diagnosis and treatment rates, and such an approach has been suggested by other authors [40]. The decision not to use Frenzel goggles or videonystagmography in our study was deliberate as we wished to reproduce the conditions faced by GPs in routine practice. Response to the EM in terms of perceived disability was not influenced by the presence or absence of nystagmus at baseline, supporting previous findings by Huebner et al [40] and Marques et al [42]. Nonetheless, we cannot completely rule out the possibility that some of the patients in the S-BPPV group may have had vestibular neuritis or vestibular migraine.

Our findings for perceived disability contrast with previous findings for the same series of patients showing that the EM reversed positive DHTs and resulted in less severe vertigo in patients with O-BPPV but not S-BPPV [25].

\section{Implications for research and/or practice}

The DHI-S is a simple tool that can be administered in a matter of minutes. It would therefore be interesting to determine cut-off points for different levels of perceived disability (none, mild, moderate, and severe).

It would also be interesting to calculate the minimal detectable change and minimal clinically important difference for the DHI-S in order to determine the relevance of changes over time.

BPPV can cause considerable disability. Early treatment of pc-BPPV using repositioning manoeuvres can result in significant improvements, highlighting the importance of prompt treatment in all patients, including those seen in primary care. It would be very interesting to determine whether performance of more than one EM would improve the outcomes observed in this study.

\section{Conclusions}

Pc-BPPV affects the quality of life of primary care patients. A single EM can improve self-perceptions of disability by around 2 points on the DHI-S scale. Nonetheless, although this difference is statistically significant, it may have little clinical relevance. 


\section{Declarations}

\section{ETHICS APPROVAL AND CONSENT TO PARTICIPATE}

The study protocol was approved by the CEIC (Clinical Research Ethics Committee) of IDIAP Jordi Gol (P12/69). As stated in the written consent form, the study was conducted in accordance with the principles of the Declaration of Helsinki and the Royal Spanish Decree 561/1993 of 16 April 1993 (Title I, Article 12). Data were processed in accordance with the Spanish Organic Law on the confidentiality of computerised data (Organic law 5/1992).

\section{CONSENT FOR PUBLICATION}

Not applicable

\section{AVAILABILITY OF DATA AND MATERIALS}

The original dataset is available upon request from the corresponding author: E-mail address: ballvejl@gmail.com.

\section{COMPETING INTERESTS}

The authors declare that they have no competing interests.

\section{FUNDING}

This project received a research grant from the Carlos III Institute of Health, Ministry of

Economy and Competitiveness (Spain), awarded on the 2013 call under the Health Strategy Action 2013-2016, within the National Research Program oriented to Societal Challenges, within the Technical, Scientific and Innovation Research National Plan 2013-2016, with reference PI13/01396, co-funded with European Union ERDF funds. It was also funded by the cycle XIV (2013) research grant from the Spanish Primary Care Network (REAP) and a predoctoral grant from the Jordi Gol Institute for Research in Primary care (IDIAP Jordi Gol) (2014/005E).

Carlos III Institute of Health, Ministry of Economy and Competitiveness (Spain), provided the main amount of funding for the development and main management of the project. REAP funded the organization of coordinating meetings and training.

IDIAP gave the grant to free up time for dedicate to the project as a predoctoral training of the author Jose Luis Ballve.

IDIAP Jordi Gol also funded the translation of this article into English.

\section{AUTHORS' CONTRIBUTIONS}

RCM, JLBM, YRM and IVB: conception, design and drafting, data collection and analysis, writing and final approval of manuscript. OCP: statistical analysis, design and drafting, analysis and interpretation of data, writing and final approval of manuscript. JAO: conception, design and drafting, analysis and interpretation of 
data, writing and final approval of manuscript. JPP, OLAA: data collection and analysis, critical review and final approval of manuscript.

\section{ACKNOWLEDGEMENTS}

The authors gratefully acknowledge the technical and scientific assistance provided by the Primary Healthcare Research Unit of Costa de Ponent Primary Healthcare University Research Institute IDIAP-Jordi Gol. We also thank Neus Profitós and Celsa Fernández who were responsible for safeguarding the randomisation sequence list. Finally, we thank all the participants of the Grupo de Estudio del Vértigo en Atención Primaria Florida: José Luis Ballvé Moreno, Yolanda Rando Matos, Estrella Rodero Pérez, Xavier Monteverde Curtó, Carles Rubio Ripollès, Noemí Moreno Farrés, Jean Carlos Gómez Nova, Johan Josué Villarreal Miñano, Diana Lizzeth Pacheco Erazo, Raquel Adroer Martori, Anna Aguilar Margalejo, Olga Lucia Arias Agudelo, Silvia Cañadas Crespo, Laura Illamola Martín, Marta Sarró Maluquer, Lluís Solsona Díaz, Rosa Sorando Alastruey (Equip d’Atenció Primària Florida Nord, Institut Català de la Salut, Hospitalet de Llobregat, Barcelona, Spain).

Ricard Carrillo Muñoz, Iván Villar Balboa, Austria Matos Méndez, Marta Bardina Santos (Equip d’Atenció Primària Florida Sud, Institut Català de la Salut, Hospitalet de Llobregat, Barcelona, Spain).

Oriol Cunillera Puértolas and Jesús Almeda Ortega (Unitat de Suport a la Recerca Costa de Ponent, Institut Universitari d'Investigació en Atenció Primària Jordi Gol Cornellà, Spain) Universitat Autònoma de Barcelona, Bellaterra (Cerdanyola del Vallès), Spain

Lead author: José Luis Ballvé Moreno.

\section{References}

1. Bhattacharyya N, Gubbels SP, Schwartz SR, Edlow JA, El-Kashlan H, Fife T, et al. Clinical Practice Guideline: Benign Paroxysmal Positional Vertigo (Update) Executive Summary. Otolaryngol Head Neck Surg. 2017 ;156(3):403-16. Available from: http://www.ncbi.nlm.nih.gov/pubmed/28248602

2. von Brevern M, Radtke A, Lezius F, Feldmann M, Ziese T, Lempert T, et al. Epidemiology of benign paroxysmal positional vertigo: a population based study. J Neurol Neurosurg Psychiatry. 2007;78(7):710-5. Available from: http://www.pubmedcentral.nih.gov/articlerender.fcgi? artid=2117684\&tool=pmcentrez\&rendertype=abstract

3. Bösner S, Schwarm S, Grevenrath P, et al. Prevalence, aetiologies and prognosis of the symptom dizziness in primary care - a systematic review. BMC Fam Pract. 2018;19(1):33. Published 2018 Feb 20. doi:10.1186/s12875-017-0695-0

4. Kim JS, Oh SY, Lee SH, Kang JH, Kim DU, Jeong SH, et al. Randomized clinical trial for apogeotropic horizontal canal benign paroxysmal positional vertigo. Neurology. 2012;78(3):159-66. Available from: http://www.ncbi.nlm.nih.gov/pubmed/22170885

5. Dix MR, Hallpike CS. The pathology symptomatology and diagnosis of certain common disorders of the vestibular system. Proc R Soc Med. 1952;45(6):341-54. Available from:

http://www.ncbi.nlm.nih.gov/pubmed/13008328

6. Haynes DS, Resser JR, Labadie RF, Girasole CR, Kovach BT, Scheker LE, et al. Treatment of benign positional vertigo using the semont maneuver: efficacy in patients presenting without nystagmus. Laryngoscope. 
2002;112:796-801.

7. Balatsouras DG, Korres SG. Subjective Benign Paroxysmal Positional Vertigo. Otolaryngol Neck Surg . 2012;146(1):98-103. Available from: http://www.ncbi.nlm.nih.gov/pubmed/21998085

8. Bronstein AM, Golding JF, Gresty MA, Mandalà M, Nuti D, Shetye A, et al. The social impact of dizziness in London and Siena. J Neurol . $2010 ; 257(2): 183-90$. Available from:

http://www.ncbi.nlm.nih.gov/pubmed/19701661

9. Carrillo R, Ballve JL, Villar I, et al. Disability perceived by primary care patients with posterior canal benign paroxysmal positional vertigo. BMC Fam Pract. 2019;20(1):156. doi:10.1186/s12875-019-1035-3).

10. Agrawal Y, Ward BK, Minor LB. Vestibular dysfunction: prevalence, impact and need for targeted treatment. J Vestib Res Equilib Orientat . $2013 ; 23(3): 113-7$. Available from:

http://www.ncbi.nlm.nih.gov/pubmed/24177344

11. Scherer S, Lisboa HRK, Pasqualotti A. Tontura em idosos: diagnóstico otoneurológico e interferência na qualidade de vida. Rev da Soc Bras Fonoaudiol . 2012;17(2):142-50. Available from:

http://www.scielo.br/scielo.php?script=sci_arttext\&pid=S1516-80342012000200007\&lang=pt

12. Yardley L, Redfern MS. Psychological factors influencing recovery from balance disorders. J Anxiety Disord . 2001;15(1-2):107-19. Available from: http://www.ncbi.nlm.nih.gov/pubmed/11388354

13. Jacobson GP, Newman CW. The development of the Dizziness Handicap Inventory. Arch Otolaryngol Head Neck Surg . 1990;116(4):424-7. Available from: http://www.ncbi.nlm.nih.gov/pubmed/2317323

14. Ardıç FN, Tümkaya F, Akdağ B, Şenol H. The subscales and short forms of the dizziness handicap inventory: are they useful for comparison of the patient groups? Disabil Rehabil . 2017;39(20):2119-22. Available from: http://www.ncbi.nlm.nih.gov/pubmed/27548005

15. Jacobson GP, Calder JH. A screening version of the Dizziness Handicap Inventory (DHI-S). Am J Otol . 1998;19(6):804-8. Available from: http://www.ncbi.nlm.nih.gov/pubmed/9831158

16. López-Escámez JA, Gómez Fiñana M, Fernández A, Sánchez Canet I, Palma MJ, Rodríguez J. Evaluation of the treatment of benign paroxysmal positional vertigo with the DHI-S questionnaire. Acta Otorrinolaringol Esp. 2001;52:660-6.

17. Hilton MP, Pinder DK. The Epley (canalith repositioning) manoeuvre for benign paroxysmal positional vertigo. In: Hilton MP, editor. The Cochrane database of systematic reviews . Chichester, UK: John Wiley \& Sons, Ltd; 2014. p. 36-7. Available from: http://doi.wiley.com/10.1002/14651858.CD003162.pub3

18. Teixeira LJ, Machado JNP. Maneuvers for the treatment of benign positional paroxysmal vertigo: a systematic review. Braz J Otorhinolaryngol . 2006;72(1):130-8. Available from:

http://www.ncbi.nlm.nih.gov/pubmed/16917565

19. Helminski JO, Zee DS, Janssen I, Hain TC. Effectiveness of particle repositioning maneuvers in the treatment of benign paroxysmal positional vertigo: a systematic review. Phys Ther. 2010;90(5):663-78.

20. Pereira AB, Santos JN, Volpe FM. Effect of Epley's maneuver on the quality of life of paroxismal positional benign vertigo patients. Braz J Otorhinolaryngol . $2010 ; 76(6): 704-8$. Available from:

http://www.ncbi.nlm.nih.gov/pubmed/21180936

21. Gámiz MJ, Lopez-Escamez JA. Health-related quality of life in patients over sixty years old with benign paroxysmal positional vertigo. Gerontology . 2004; 50(2):82-6. Available from:

http://www.ncbi.nlm.nih.gov/pubmed/14963374

Page $10 / 21$ 
22. Lopez-Escamez JA, Gamiz MJ, Fernandez-Perez A, Gomez-Fiñana M. Long-term outcome and health-related quality of life in benign paroxysmal positional vertigo. Eur Arch Otorhinolaryngol . 2005;262(6):507-11. Available from: http://www.ncbi.nlm.nih.gov/pubmed/15942805

23. Munoz JE, Miklea JT, Howard M, Springate R, Kaczorowski J. Canalith repositioning maneuver for benign paroxysmal positional vertigo: randomized controlled trial in family practice. Can Fam Physician . 2007;53(6):1049-53, 1048. Available from:

http://www.ncbi.nlm.nih.gov/pubmed/17872784\%5Cnhttp://www.pubmedcentral.nih.gov/articlerender.fcgi? artid=PMC1949221

24. Ballve Moreno JL, Carrillo Muñoz R, Villar Balboa I, Rando Matos Y, Arias Agudelo OL, Vasudeva A, et al. Effectiveness of the Epley's maneuver performed in primary care to treat posterior canal benign paroxysmal positional vertigo: study protocol for a randomized controlled trial. Trials . 2014;15(1):179. Available from: http://www.pubmedcentral.nih.gov/articlerender.fcgi?artid=4043960\&tool=pmcentrez\&rendertype=abstract

25. Ballvé JL, Carrillo-Muñoz R, Rando-Matos Y, Villar I, Cunillera O, Almeda J, et al. Effectiveness of the Epley manoeuvre in posterior canal benign paroxysmal positional vertigo: a randomised clinical trial in primary care. Br J Gen Pract . 2019 ;69(678):e52-60. Available from: http://www.ncbi.nlm.nih.gov/pubmed/30510098

26. Dieterich $\mathrm{M}$, Obermann M, Celebisoy N. Vestibular migraine: the most frequent entity of episodic vertigo. J Neurol . 2016;263 Suppl:S82-9. Available from: http://www.ncbi.nlm.nih.gov/pubmed/27083888

27. Headache Classification Committee of the International Headache Society (IHS). The International Classification of Headache Disorders, 3rd edition (beta version). Cephalalgia . 2013;33(9):629-808. Available from: http://www.ncbi.nlm.nih.gov/pubmed/23771276

28. Froehling D a, Bowen JM, Mohr DN, Brey RH, Beatty CW, Wollan PC, et al. The canalith repositioning procedure for the treatment of benign paroxysmal positional vertigo: a randomized controlled trial. . Vol. 75, Mayo Clinic proceedings. Mayo Clinic. 2000. Available from: http://dx.doi.org/10.4065/75.7.695

29. Cunillera O.Tobit Models. Encyclopedia of quality of life and well-being research. In: Edited by Michalos AC, Springer, Netherlands, 2014, pp6671-6676.

30. Greene, W.H. Econometric Analysis. 5th Edition, Prentice Hall, Upper Saddle River. 2003, pp 764.

31. Enloe LJ, Shields RK. Evaluation of health-related quality of life in individuals with vestibular disease using disease-specific and general outcome measures. Phys Ther. 1997;77(9):890-903.

32. Moreno NS, Do Rego André AP. Number of maneuvers need to get a negative Dix-Hallpike test. Braz J Otorhinolaryngol 2009; 75(5): 650-653.

33. Petri M, Chirilă M, Bolboacă SD, Cosgarea M. Health-related quality of life and disability in patients with acute unilateral peripheral vestibular disorders. Braz J Otorhinolaryngol . 2016;83(6):611-8. Available from: http://www.ncbi.nlm.nih.gov/pubmed/27595924

34. Obermann M, Bock E, Sabev N, Lehmann N, Weber R, Gerwig M, et al. Long-term outcome of vertigo and dizziness associated disorders following treatment in specialized tertiary care: the Dizziness and Vertigo Registry (DiVeR) Study. J Neurol . 2015;262(9):2083-91. Available from:

http://www.ncbi.nlm.nih.gov/pubmed/26092518.

35. Silva CN Da, Ribeiro KMOBDF, Freitas RVDM, Ferreira LMDBM, Guerra RO. Vertiginous Symptoms and Objective Measures of Postural Balance in Elderly People with Benign Paroxysmal Positional Vertigo 
Submitted to the Epley Maneuver. Int Arch Otorhinolaryngol . 2016;20(1):61-8. Available from:

http://www.ncbi.nlm.nih.gov/pubmed/26722348

36. Neuhauser HK, Radtke A, von Brevern M, Lezius F, Feldmann M, Lempert T. Burden of dizziness and vertigo in the community. Arch Intern Med . 2008;168(19):2118-24. Available from:

http://www.ncbi.nlm.nih.gov/pubmed/18955641

37. Ribeiro KMOB de F, Ferreira LM de BM, Freitas RV de M, Silva CN da, Deshpande N, Guerra RO. "Positive to Negative" Dix-Hallpike test and Benign Paroxysmal Positional Vertigo recurrence in elderly undergoing Canalith Repositioning Maneuver and Vestibular Rehabilitation. Int Arch Otorhinolaryngol . 2016;20(4):34452. Available from: http://www.ncbi.nlm.nih.gov/pubmed/27746838

38. Chen Z-J, Chang C-H, Hu L-Y, Tu M-S, Lu T, Chen P-M, et al. Increased risk of benign paroxysmal positional vertigo in patients with anxiety disorders: a nationwide population-based retrospective cohort study. BMC Psychiatry . 2016;16(1):238. Available from: http://bmcpsychiatry.biomedcentral.com/articles/10.1186/s12888-016-0950-2

39. Ferrari S, Monzani D, Baraldi S, Simoni E, Prati G, Forghieri M, et al. Vertigo "in the pink": The impact of female gender on psychiatric-psychosomatic comorbidity in benign paroxysmal positional vertigo patients. Psychosomatics . 2014;55(3):280-8. Available from: http://www.ncbi.nlm.nih.gov/pubmed/23756120

40. Huebner AC, Lytle SR, Doettl SM, Plyler PN, Thelin JT. Treatment of objective and subjective benign paroxysmal positional vertigo. J Am Acad Audiol . 2013;24(7):600-6. Available from: http://www.scopus.com/inward/record.url?eid=2-s2.0-84884798325\&partnerlD=tZOtx3y1

41. Tirelli G, D'Orlando E, Giacomarra V, Russolo M. Benign positional vertigo without detectable nystagmus. Laryngoscope. 2001;111(6):1053-1056. doi:10.1097/00005537-200106000-00022

42. Marques PS, Castillo R, Santos M, Perez-Fernandez N. Repositioning nystagmus: prognostic usefulness? Acta Otolaryngol . 2014;134(5):491-6. Available from: http://www.ncbi.nlm.nih.gov/pubmed/247022230.

\section{Tables}

Table 1 Characteristics of the study participants overall and by intervention 


\begin{tabular}{|c|c|c|c|c|c|}
\hline & $\mathbf{N}$ & Overall & $\begin{array}{l}\text { Sham manoeuvre } \\
(\mathrm{n}=68)\end{array}$ & $\begin{array}{l}\text { Epley manoeuvre } \\
(\mathrm{n}=66)\end{array}$ & $\begin{array}{l}P \\
\text { value }\end{array}$ \\
\hline Female, n (\%) & 134 & $\begin{array}{c}102 \\
(76.12)\end{array}$ & $50(73.53)$ & 52 (78.79) & 0.546 \\
\hline $\begin{array}{l}\text { Age, median, } \\
\text { (IQR) }\end{array}$ & 134 & $\begin{array}{l}52.00 \\
(38.25 \\
68.00)\end{array}$ & $\begin{array}{c}54.00 \\
(40.75-72.00)\end{array}$ & $\begin{array}{c}50.50 \\
(35.25-64.00)\end{array}$ & 0.060 \\
\hline $\begin{array}{l}\text { Positive DHT with } \\
\text { nystagmus, n (\%) }\end{array}$ & 134 & $54(40.30)$ & 25 (36.76) & $29(43.94)$ & 0.482 \\
\hline Anxiety, n (\%) & 130 & $33(25.38)$ & $15(22.73)$ & $18(28.12)$ & 0.548 \\
\hline Depression, n (\%) & 130 & $30(23.08)$ & $15(22.73)$ & $15(23.44)$ & 1.000 \\
\hline Benzodiazepines, n (\%) & 134 & $24(17.91)$ & $11(16.18)$ & $13(19.70)$ & 0.656 \\
\hline Antidepressants, n (\%) & 134 & $27(20.15)$ & $13(19.12)$ & $14(21.21)$ & 0.831 \\
\hline Medication for vertigo, $\mathrm{n}(\%)$ & 134 & $78(58.21)$ & $37(54.41)$ & $41(62.12)$ & 0.386 \\
\hline
\end{tabular}

DHT $=$ Dix-Hallpike test. IQR = interquartile range.

Table 2a Baseline evaluation 


\begin{tabular}{|c|c|c|c|c|c|c|}
\hline & $\mathbf{N}$ & $\begin{array}{l}\text { Missing } \\
\text { value }\end{array}$ & $\begin{array}{c}\text { DHI-S } \\
\text { Whole group }\end{array}$ & $\begin{array}{c}\text { DHI-S } \\
\text { Sham maneuver } \\
(n=68)\end{array}$ & $\begin{array}{c}\text { DHI-S } \\
\text { Epley maneuver } \\
(n=66)\end{array}$ & $\begin{array}{c}P \\
\text { value }\end{array}$ \\
\hline & 134 & 0 & $\begin{array}{c}16.0(8.0- \\
22.0)\end{array}$ & $14.0(8.0-22.0)$ & $16.0(10.0-22.0)$ & 0.537 \\
\hline \multicolumn{7}{|c|}{ By sex } \\
\hline Male & 32 & 0 & $\begin{array}{c}10.0(6.0- \\
14.0)\end{array}$ & $7.0(6.0-13.5)$ & $11.0(8.0-21.0)$ & 0.053 \\
\hline Female & 102 & 0 & $\begin{array}{c}16.0(10.5- \\
24.0)\end{array}$ & $16.0(10.5-25.5)$ & $16.0(11.5-24.0)$ & 0.596 \\
\hline \multicolumn{7}{|c|}{ By nystagmus } \\
\hline $\begin{array}{c}\text { S- } \\
\text { BPPV }\end{array}$ & 80 & 0 & $\begin{array}{c}16.0(10.0- \\
24.0)\end{array}$ & $16.0(10.0-24.0)$ & $18.0(14.0-24.0)$ & 0.545 \\
\hline $\begin{array}{c}\text { O- } \\
\text { BPPV }\end{array}$ & 54 & 0 & $\begin{array}{c}12.0(8.0- \\
18.0)\end{array}$ & $12.0(6.0-16.0)$ & $12.0(8.0-18.0)$ & 0.595 \\
\hline
\end{tabular}

Table $2 \mathrm{~b}$ Evaluation at 1 week 


\begin{tabular}{|c|c|c|c|c|c|c|}
\hline & $\mathbf{N}$ & $\begin{array}{c}\text { Missing } \\
\text { value }\end{array}$ & $\begin{array}{c}\text { DHI-S } \\
\text { Whole grup }\end{array}$ & $\begin{array}{c}\text { DHI-S } \\
\text { Sham maneuver } \\
(n=68)\end{array}$ & $\begin{array}{c}\text { DHI-S } \\
\text { Epley maneuver } \\
(\mathrm{n}=66)\end{array}$ & $\begin{array}{c}P \\
\text { value }\end{array}$ \\
\hline & 134 & 9 & $\begin{array}{c}8.0(2.0- \\
14.0)\end{array}$ & $8.0(4.0-18.0)$ & $6.0(0.0-14.0)$ & 0.175 \\
\hline \multicolumn{7}{|c|}{ By sex } \\
\hline Male & 32 & 4 & $2.0(0.0-6.5)$ & $4.0(2.0-8.0)$ & $2.0(0.0-3.0)$ & 0.347 \\
\hline Female & 102 & 5 & $\begin{array}{c}10.0(4.0- \\
18.0)\end{array}$ & $10.0(5.0-21.0)$ & $9.0(0.5-14.0)$ & 0.127 \\
\hline \multicolumn{7}{|c|}{ By nystagmus } \\
\hline $\begin{array}{c}\text { S- } \\
\text { BPPV }\end{array}$ & 80 & 6 & $\begin{array}{c}8.0(2.0- \\
14.0)\end{array}$ & $8.0(3.5-15.0)$ & $7.0(0.0-14.0)$ & 0.662 \\
\hline $\begin{array}{c}\text { O- } \\
\text { BPPV }\end{array}$ & 54 & 3 & $\begin{array}{c}8.0(2.0- \\
15.0)\end{array}$ & $9.0(4.0-26.5)$ & $4.0(1.0-13.0)$ & 0.126 \\
\hline
\end{tabular}

Table 2c Evaluation at 1 month 


\begin{tabular}{|c|c|c|c|c|c|c|}
\hline & $\mathbf{N}$ & $\begin{array}{c}\text { Missing } \\
\text { value }\end{array}$ & $\begin{array}{l}\text { DHI-S } \\
\text { Whole } \\
\text { group }\end{array}$ & $\begin{array}{c}\text { DHI-S } \\
\text { Sham maneuver } \\
\text { group } \\
(n=68)\end{array}$ & $\begin{array}{c}\text { DHI-S } \\
\text { Epley maneuver } \\
\text { group } \\
(n=66)\end{array}$ & $\begin{array}{c}P \\
\text { value }\end{array}$ \\
\hline & 134 & 17 & $\begin{array}{c}0.0(0.0- \\
10.0)\end{array}$ & $2.0(0.0-12.0)$ & $0.0(0.0-6.0)$ & 0.140 \\
\hline \multicolumn{7}{|c|}{ By sex } \\
\hline Male & 32 & 6 & $0.0(0.0-7.0)$ & $0.0(0.0-6.0)$ & $0.0(0.0-6.0)$ & 0.932 \\
\hline Female & 102 & 11 & $\begin{array}{c}0.0(0.0- \\
12.0)\end{array}$ & $4.0(0.0-12.0)$ & $0.0(0.0-6.0)$ & 0.079 \\
\hline \multicolumn{7}{|c|}{ By nystagmus } \\
\hline $\begin{array}{c}\text { S- } \\
\text { BPPV }\end{array}$ & 80 & 12 & $\begin{array}{c}0.0(0.0- \\
12.0)\end{array}$ & $2.0(0.0-12.0)$ & $0.0(0.0-6.0)$ & 0.290 \\
\hline $\begin{array}{c}\text { O- } \\
\text { BPPV }\end{array}$ & 54 & 5 & $\begin{array}{c}0.0(0.0- \\
10.0)\end{array}$ & $2.0(0.0-11.0)$ & $0.0(0.0-7.0)$ & 0.323 \\
\hline
\end{tabular}

Tabla 2 d. Evaluation at 1 year 


\begin{tabular}{|c|c|c|c|c|c|c|}
\hline & $\mathbf{N}$ & $\begin{array}{l}\text { Missing } \\
\text { value }\end{array}$ & $\begin{array}{l}\text { DHI-S } \\
\text { Whole } \\
\text { group }\end{array}$ & $\begin{array}{c}\text { DHI-S } \\
\text { Sham maneuver } \\
\text { group } \\
(\mathrm{n}=68)\end{array}$ & $\begin{array}{c}\text { DHI-S } \\
\text { Epley maneuver } \\
\text { group } \\
(\mathrm{n}=66)\end{array}$ & $\begin{array}{c}P \\
\text { value }\end{array}$ \\
\hline & 134 & 22 & $\begin{array}{c}0.0(0.0- \\
2.5)\end{array}$ & $0.0(0.0-4.0)$ & $0.0(0.0-2.0)$ & 0.506 \\
\hline \multicolumn{7}{|c|}{ By sex } \\
\hline Male & 32 & 7 & $\begin{array}{c}0.0(0.0- \\
4.0)\end{array}$ & $0.0(0.0-3.5)$ & $0.0(0.0-7.0)$ & 0.926 \\
\hline Female & 102 & 15 & $\begin{array}{c}0.0(0.0- \\
2.0)\end{array}$ & $0.0(0.0-4.0)$ & $0.0(0.0-0.5)$ & 0.520 \\
\hline \multicolumn{7}{|c|}{ By nystagmus } \\
\hline $\begin{array}{c}\text { S- } \\
\text { BPPV }\end{array}$ & 80 & 13 & $\begin{array}{c}0.0(0.0- \\
4.0)\end{array}$ & $0.0(0.0-5.5)$ & $0.0(0.0-2.0)$ & 0.472 \\
\hline $\begin{array}{c}\text { O- } \\
\text { BPPV }\end{array}$ & 54 & 9 & $\begin{array}{c}0.0(0.0- \\
0.0)\end{array}$ & $0.0(0.0-0.0)$ & $0.0(0.0-0.0)$ & 0.899 \\
\hline
\end{tabular}

Table 3 Multivariate mixed-effects regression 
Marginal Effect

(95\%CI)

(Intercept)

Treatment group

Baseline DHI-S score

Follow-up

Nystagmus at baseline

Nystagmus at baseline Follow-

up
$-1.05(-3.72-1.76)$

Sham group

(reference)

$$
\text { Epley manoeuvre group } \quad-2.03 \text { (-4.59 to -0.06) } 0.045
$$

Week (reference)

value

0.518

$0.37(0.27-0.53) \quad<0.001$

$\begin{array}{ccc}\text { Month } & -3.09(-6.74-0.17) & 0.130 \\ \text { Year } & -1.26(-5.62-2.61) & 0.558\end{array}$

$1.78(-0.37-4.18) \quad 0.185$
Baseline nystagmus after $1 \quad-3.95$ (-9.01 to -0.02) $\quad 0.039$
year

Baseline DHI-S score Follow- $\quad$ Baseline DHI-S after 1 month $\quad-0.03(-0.20-0.14) \quad 0.775$ up

Baseline DHI-S after 1 year $\quad-0.32(-0.54$ to -0.09$) \quad 0.003$

Final model built following stepwise backward selection of variables using the Akaike Information Criterion from an initial model featuring treatment adjusted for follow-up, baseline DHI-S score, sex, nystagmus at baseline, and three-way interactions between these factors and treatment and follow-up. DHI-S =Dizziness Handicap Inventory - Screening version.

\section{Figures}




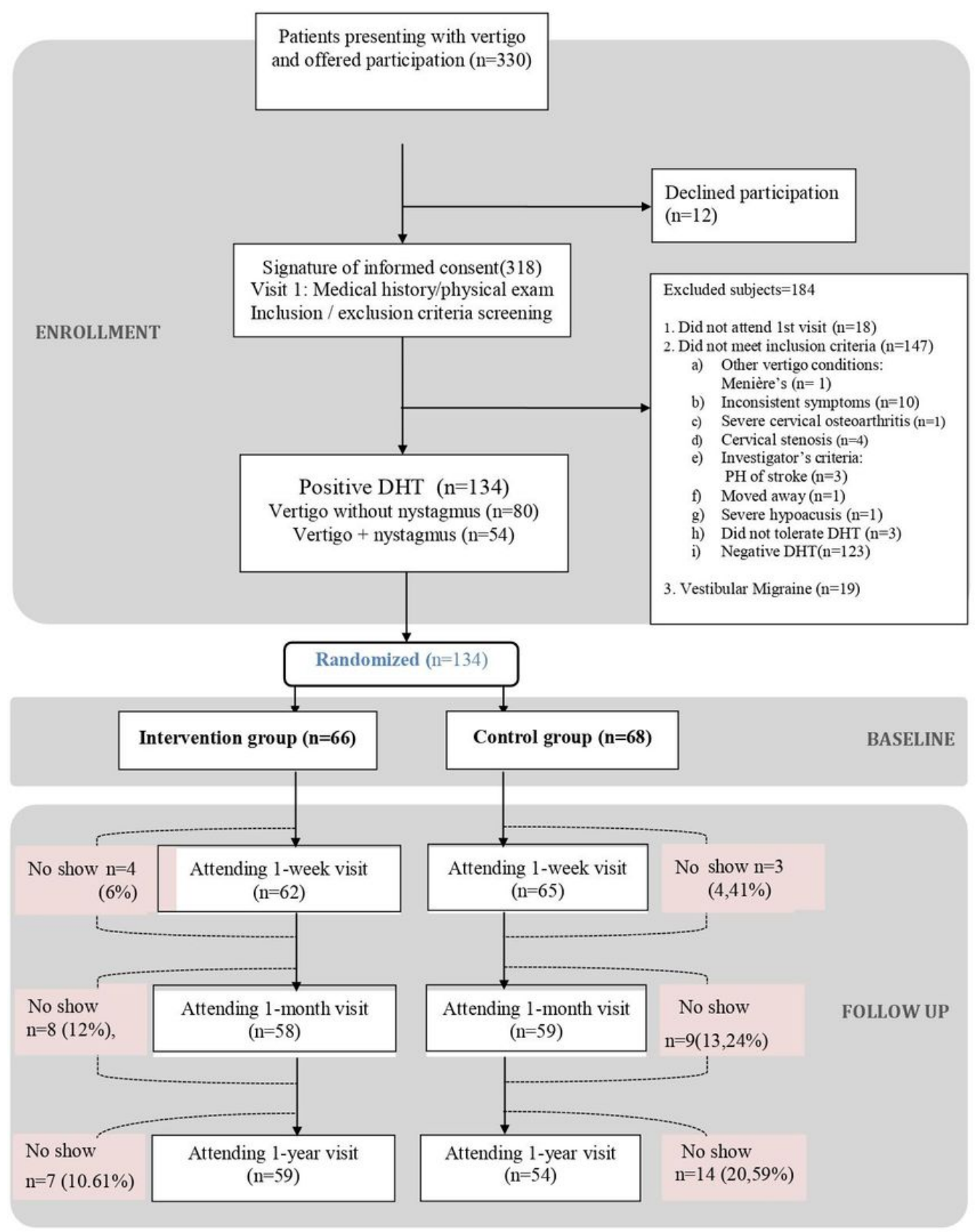

Figure 1. Flowchart of participants

$\mathrm{PH}=$ personal history $\mathrm{DHT}=$ Dix Hallpike Test

\section{Figure 1}

\section{Flowchart of participants}


Figure 2 Expected values from Table 3 estimated by the Tobit model with the best predictive accuracy according to treatment received (Epley manoeuvre

[interv] vs sham manoeuvre [control]). Base $\mathrm{DHI}=$ baseline Dizziness Handicap Inventory-Screening Version score.
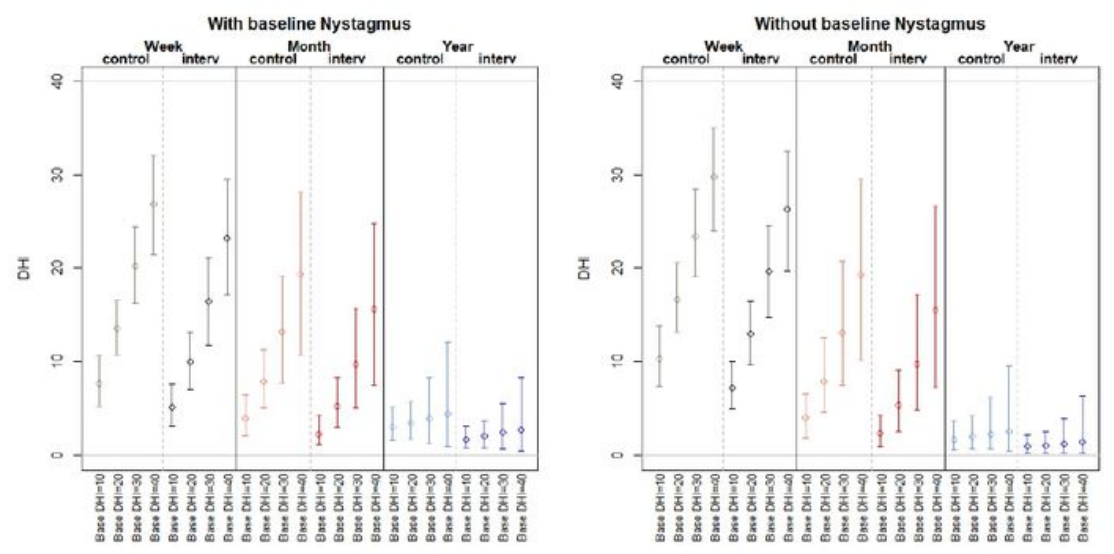

Figure 2

Expected values from Table 3 estimated by the Tobit model with the best predictive accuracy according to treatment received (Epley manoeuvre [interv] vs sham manoeuvre [control]).

\section{Supplementary Files}

This is a list of supplementary files associated with this preprint. Click to download.

- CONSORTchecklist.docx 
- SupplementarymaterialAppendix1.docx

Page 21/21 